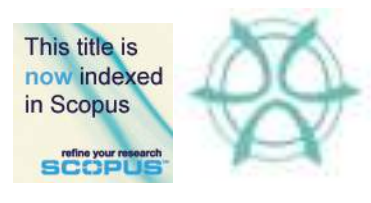

PLANNING MALAYSIA:

Journal of the Malaysian Institute of Planners

SPECIAL ISSUE IV (2016), Page 285 - 294

\title{
CO-BENEFIT MODELING AND OPTIMIZATION OF AIR POLLUTION CONTROL IN ISKANDAR MALAYSIA: A METHODOLOGY USING BEnMAP
}

\author{
Nadhirah Nordin ${ }^{1}$, M. Rafee Majid ${ }^{2}$, Ho Chin Siong ${ }^{3}$ \& Gakuji Kurata ${ }^{4}$ \\ ${ }^{1,2,3}$ UNIVERSITI TEKNOLOGI MALAYSIA \\ ${ }^{4}$ KYOTO UNIVERSITY, JAPAN
}

\begin{abstract}
Malaysia is currently experiencing issues of local as well as transboundary air pollution. The issues are especially felt in areas that record high economic growth and rapid urbanization such as Iskandar Malaysia, a fast evolving economic-growth corridor in Southeast Asia. This has led to increased rate of particulate matter emissions, which further led to increase in the rate of respiratory-related health incidences. Many epidemiological studies have proven that particulate matters in the ambient air are associated with adverse health effects. This will affect the existing and future economy of Iskandar Malaysia, where the exposed population may lose their workdays and face increased medical spending. This study focuses on quantifying health and economic benefits from the reduction of particulate matter with a size of 10 micrometers or less in diameter (PM10) using the Environmental Benefits Mapping and Analysis Program (BenMAP) by US EPA. Health impact functions are used to quantify the relationship between a change in PM10 level and number of related health effects among the exposed population. The samples for this research include a continuous monitoring data on the 2014 monthly average of daily PM10, the 2014 population projection of Malaysian Census Data and the PM10 related health cases for 2014 which are focused in the Iskandar Malaysia region. PM10 data are collected from monitoring stations operated by the Department of Environment (DOE). Respiratory related cases such as Upper Respiratory Tract Infection, which is categorized as J10 in International Classification of Diseases, are collected from selected clinics within the study area. The final outcome of the modeling exercise compares the co-benefits of air pollution reduction between the baseline scenario and the control scenario for PM10 level in Iskandar Malaysia. The results of this study are useful in optimizing and improving the existing policies and strategies for controlling air pollution and PM10 emission in Iskandar Malaysia.
\end{abstract}

Keyword: Air pollution, particulate matter emission, PM10, health benefits, BenMAP

\section{INTRODUCTION}

The issue of air pollution has long been discussed globally and air pollution has been proven to have impact on the exposed population. Malaysia is one of the developing countries in Asian region that is not excluded from experiencing serious issues related to air pollution. Increasing urbanisation in Malaysia has led to a growing concern on the 
Nadhirah Nordin, M. Rafee Majid, Ho Chin Siong \& Gakuji Kurata

Co-Benefit Modeling and Optimization of Air Pollution Control in Iskandar Malaysia: A Methodology using BenMAP

ambient air quality. As to date, Iskandar Malaysia is one of the regions that undergoes rapid developments in Malaysia but suffers deteriorating level of air quality. The current population in the region is exposed to the deteriorating ambient air quality and is a potential threat that is ever becoming a reality.

The purpose of this research is to explore substantially on the health and monetized benefits of the emission reduction scenario in the air pollution level among the exposed population of Iskandar Malaysia. This study focused on air particles the size of smaller than $10 \mu \mathrm{m}$ in aerodynamic diameter $\left(\mathrm{PM}_{10}\right) . \mathrm{PM}_{10}$ has been a recent concern where epidemiological studies have proven that continuous exposure to air pollution especially particles of less than $10 \mu \mathrm{m}$ in size affects the health of the exposed. Many epidemiological works around the world continuously associates $\mathrm{PM}_{10}$ to serious adverse health effects including daily mortality which consists of all-cause, cardiovascular disease and respiratory disease (Dai et al. 2004; Hwang et al. ,2002) and is also associated with higher prevalence of respiratory symptoms (Hong et. al, 2001). Hwang et al. (2007) reported that lung cancer incidence and mortality rates in women increased up to $65 \%$ and $27 \%$ when a higher $\mathrm{PM}_{10}$ concentration was applied. Furthermore, a study done by Iwai et al. (2005) reported that a significant correlation was observed between SPM (Suspended Particulate Matter) and ischemic heart disease or hypertensive heart disease in both males and females. As study by Pan et al. (2007) proved, symptoms such as asthma, emergency department visits, hospital admissions for respiratory and cardiovascular disease decreases when a clean-energy-use scenario (decreased in $\mathrm{PM}_{10}$ concentrations) was implemented and compared to the baseline scenario.

Many studies regarding $\mathrm{PM}_{10}$ health effects have been done in countries in Asia such as in China, Japan and Thailand. But, only a number of studies have been done regarding the level of $\mathrm{PM}_{10}$ and the associated health effects in Malaysia. A research project report by UKM Pakarunding (2004) discussed on the associations of $\mathrm{PM}_{10}$ increments with the significant Relative Risks (RR) outcomes for respiratory and cardiovascular morbidity. In this research we try to simulate the impact of a reduced $\mathrm{PM}_{10}$ level as well as its monetized benefits through the Environmental Benefits and Mapping Analysis program (BenMAP) developed by US EPA. To date, there are currently no studies done yet regarding this particular field in Malaysia.

Like other developing countries, Malaysia has developed its own National Air Quality Monitoring Program that is mainly governed by Alam Sekitar Malaysia Bhd (ASMA) and the Department of Environment (DOE). So far, ASMA has established monitoring stations to capture particles that contribute to air pollution such as $\mathrm{CO}, \mathrm{SO}_{2}$, $\mathrm{O}_{3}$ and $\mathrm{PM}_{10}$ in both Peninsular Malaysia as well as in the Sabah and Sarawak. The focus has been to only capture $\mathrm{PM}_{10}$ and other particles but less research is done on its contribution to serious health effects among the exposed population in Malaysia.

The DOE monitoring station that are within Iskandar Malaysia's vicinity are located in Pasir Gudang, Johor Bahru and Tampoi. Since this research uses the population data input that is based on the 2010 Malaysia Census Data, all the other data inputs such as $\mathrm{PM}_{10}$ monitoring data and health incidence data are based on the year 2010. This research only uses the $\mathrm{PM}_{10}$ monitoring data available for the year 2010 that only includes Pasir Gudang and Johor Bahru stations. To address the needs to conduct this research, Figure 1 illustrates the daily mean of $\mathrm{PM}_{10}$ monitoring data for 2010 in both stations as well as the recommended guidelines of daily mean of $\mathrm{PM}_{10}$ by World Health Organization 
(WHO), US Environmental Protection Agency (US EPA) and the guideline set by DOE Malaysia. This shows alarming trends of $\mathrm{PM}_{10}$ in both stations where $\mathrm{PM}_{10}$ exceeded the recommended WHO guideline for daily mean of $\mathrm{PM}_{10}$ and even though Malaysia's and US EPA's recommended guidelines for $\mathrm{PM}_{10}$ daily mean is higher, $\mathrm{PM}_{10}$ level is still at an alarming rate because it exceeded the WHO daily mean guideline for $\mathrm{PM}_{10}$. The occurrence of $\mathrm{PM}_{10}$ daily mean exceeding Malaysia and US EPA guidelines on June and October 2010 shows the incident of trans boundary haze that occurred in Malaysia and neighboring countries. Thus, there is an urgent need to conduct this research in Iskandar Malaysia region before the matter gets worst.

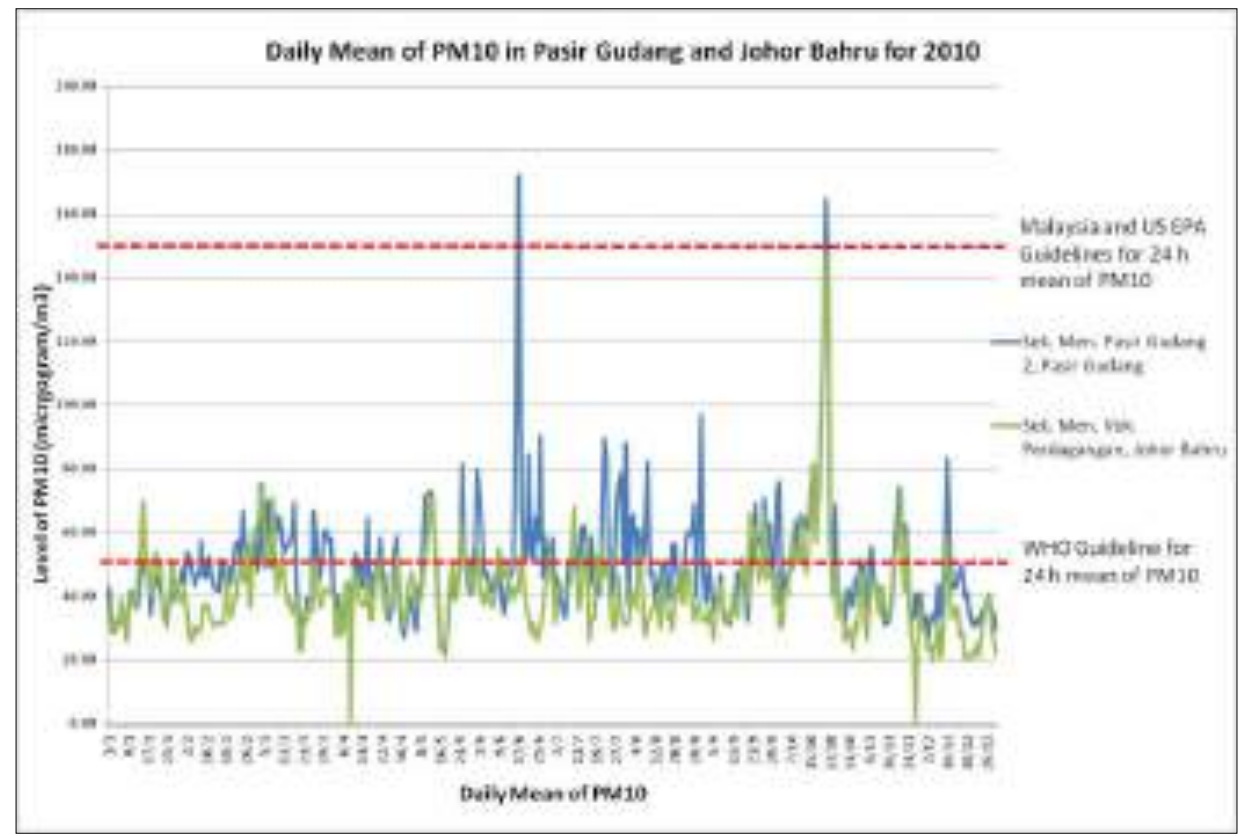

Figure 1: Daily Means of PM10 in Pasir Gudang and Johor Bahru stations in 2010

\section{BenMAP OPERATION}

BenMAP is used to estimate the number of avoidable deaths and the monetized value of each of the health cases avoided and to illustrate the economical and health benefits of a $\mathrm{PM}_{10}$ reduction scenario. Figure 2 shows the framework of the policy analysis approach in BenMAP. There are three major stages involved in BenMAP analysis which are: i) producing the air quality surface; 2) constructing health impact configuration; and 3) evaluating the economic costs which involves aggregating, pooling and valuating the reduced health cases. All of these stages have to be completed in order to conduct the analysis step to obtain the results. This paper explains our current progress up to the methodology stage.

The relationship between a change in the concentration of a pollutant level $\left(\mathrm{PM}_{10}\right)$ and the change in the incidence of a $\mathrm{PM}_{10}$-related health effects are quantified by using 
Nadhirah Nordin, M. Rafee Majid, Ho Chin Siong \& Gakuji Kurata

Co-Benefit Modeling and Optimization of Air Pollution Control in Iskandar Malaysia: A Methodology using BenMAP

health impact functions (He et al. , 2010) obtained from previous epidemiology studies that are done in Asia. A general form of health impact function is as follows:

$$
\mathrm{y}=\mathrm{y}_{\mathrm{o}}\left(e^{\beta \Delta \mathrm{x}}-1\right) \text { Pop }
$$

where $y_{0}=$ baseline incident rate for the health endpoint, $\beta=$ risk coefficient from epidemiological study, $\Delta x=$ change in air quality and Pop $=$ population of interest.

Eq. 1 lists the variables needed in a health impact function for a certain health incidence and these functions are also called concentration-response functions (CRF). As to date, the current health impact functions that are available in epidemiology studies are mostly from the developed countries like U.S., Europe and in some Asian countries. So the health impact function for each of the health incidence that will be analyzed in this research will refer to health impact functions in studies that are done in Asian countries, preferably developing countries. This will reduce the uncertainty of this research where health impact functions of similar environment should be used to make the study feasible. The health impact functions are chosen from various studies on the $\mathrm{PM}_{10}$-related health effects and will be adjusted according to Iskandar Malaysia's suitability based on the current baseline incidence rate of health effects and current level of $\mathrm{PM}_{10}$

Economic costs of these incidence changes can then be estimated by multiplying the changes in incidence by an estimated unit value for the health endpoint (He et al. , 2010). These are obtained by using valuation functions from other related epidemiology studies that are done in Asia. One example of the significance of economic benefits in the $\mathrm{PM}_{10}$ reduction scenario is that by Chen et. al. (2007), where the implementation of low carbon energy scenarios could reach an economic benefits up to U.S.\$507.31 million to U.S. $\$ 1.49$ billion in 2010 . 


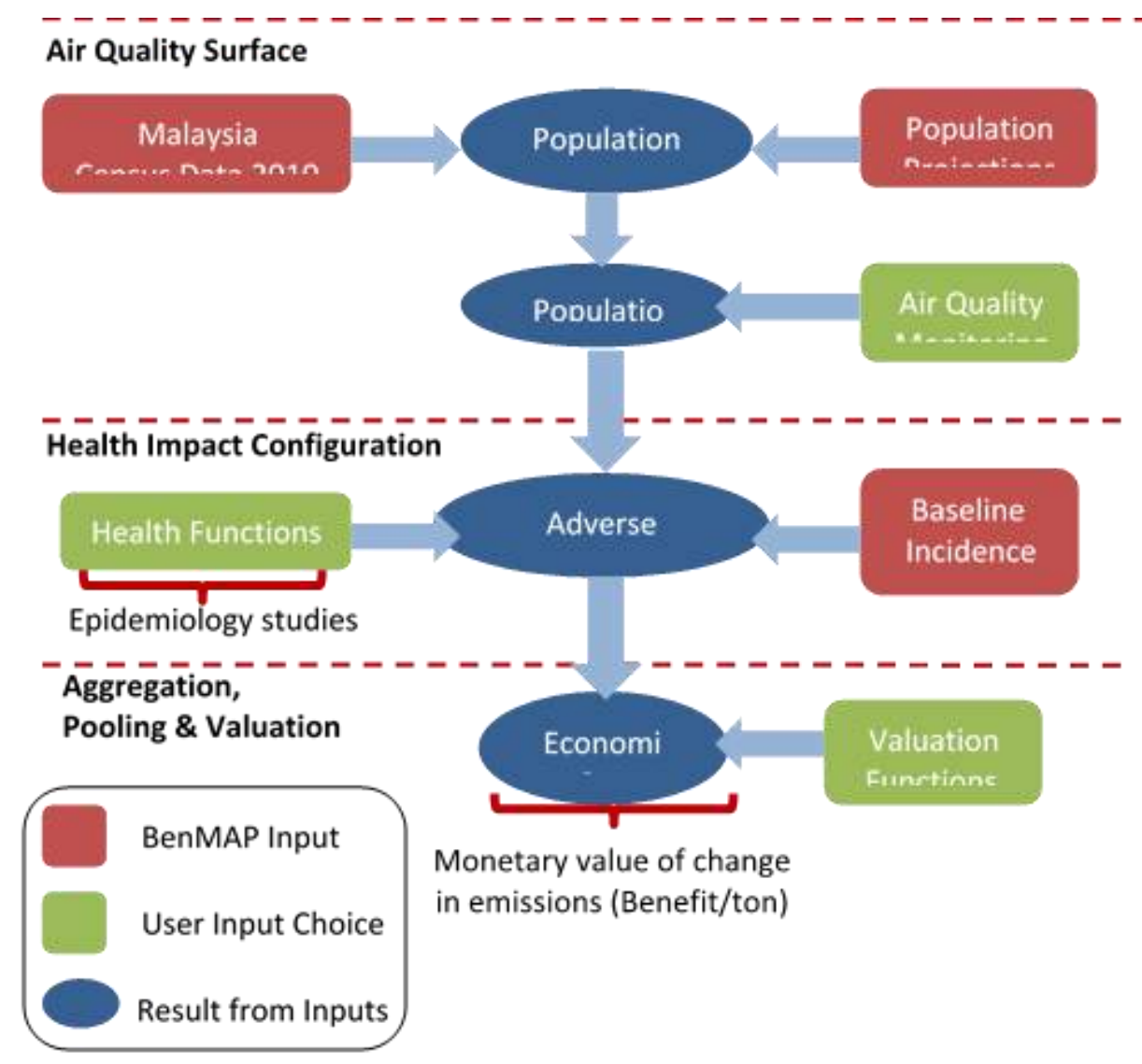

Figure 2: BenMAP Policy Analysis Approach

\section{Data Requirements}

The three major stages in BenMAP analysis mentioned above could be further divided into five distinct phases. The first phase in operating BenMAP involves loading externally created data in the format that BenMAP recognizes. The second and third phases involve calculating population estimates and population exposure. The fourth phase is about configuring the health impacts and the last phase is for obtaining the economic costs and benefits from the previous results of the health impacts analysis.

All the data inputs will be adjusted according to formats that BenMAP recognizes. The data input include grid definitions, pollutants to be analyzed, pollutant monitoring datasets, incidence and prevalence datasets, population datasets, health impact functions and valuation functions from epidemiological studies. Grid definitions consist of irregular and regular shapefiles where they illustrate the boundary of Iskandar Malaysia as well as square grids to cover the Iskandar Malaysia region. These square grids are needed in order to show current population estimates and to produce population exposures as well as illustrating the results of the analysis in BenMAP in the future. 
Nadhirah Nordin, M. Rafee Majid, Ho Chin Siong \& Gakuji Kurata

Co-Benefit Modeling and Optimization of Air Pollution Control in Iskandar Malaysia: A Methodology using BenMAP

Figure 3 illustrates the estimated population based on Malaysia Census Data for 2010 at the district level apportioned according to each grid.

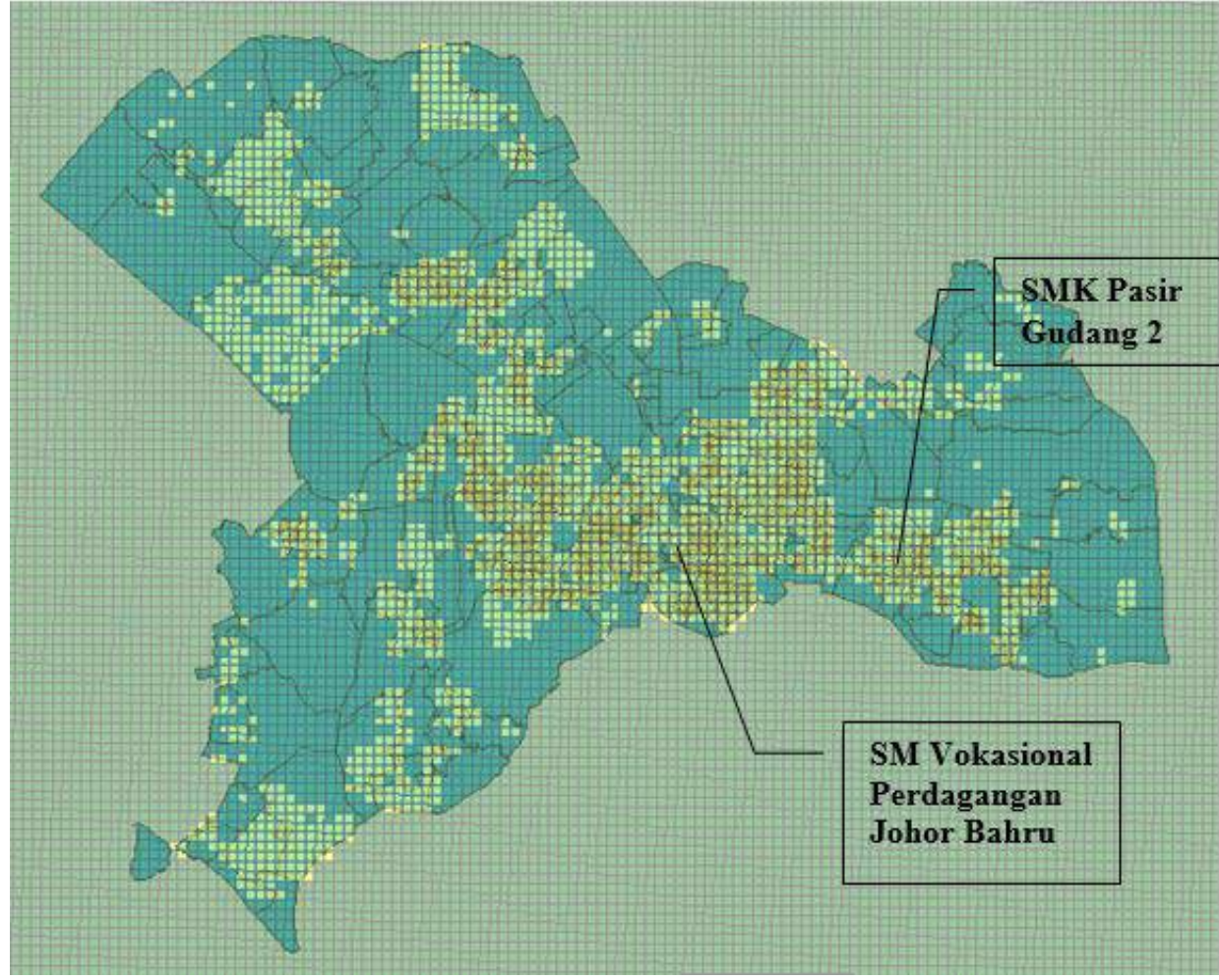

Figure 3: Population estimates based on Malaysia Census Data 2010 for Iskandar Malaysia and the location of DOE monitoring stations

\section{Population Estimates}

BenMAP inputs are associated with the existing data on population estimates by which, in Malaysia, the population data used is the Malaysia Census Data for 2010. The data are arranged in Excel format according to the BenMAP Users Manual for 2012. Since the population census are distributed the small census districts in Iskandar Malaysia, the population grid are produced based on the number of people living in each grid to tally with the total number of people living in a certain district.

\section{Population Exposure}

In order to obtain population exposure to air pollution, $\mathrm{PM}_{10}$ monitoring data are obtained and prepared in the format that BenMAP recognizes. The monitoring data are obtained from DOE stations in Johor Bahru and Pasir Gudang. Even though there are limited numbers of monitoring stations in Iskandar Malaysia, BenMAP have the ability to average the monitoring data for the whole region by using the Voronoi Neighbor Averaging (VNA) process. According to the BenMAP Users Manual for 2012, VNA 
process first identifies the set of monitors that surround each grid cell center and calculates the inverse-distance weighted average for the neighboring monitors (in this case, the neighboring monitors are in Johor Bahru and Pasir Gudang). So the interpolation of the monitoring data points for each grid across the region can be done.

The variables in the monitoring data consist of metrics, seasonal metrics, statistic (annual metric) and values. The metric used for $\mathrm{PM}_{10}$ reduction scenario analysis in this research is calculated in Daily Average Values in BenMAP. Seasonal metrics are calculated based on the average values of $\mathrm{PM}_{10}$ in each month so that makes 12 values of seasonal metrics for 12 months in 2010. Since $\mathrm{PM}_{10}$ are observed daily, a value of 365 (days per year) is obtained from DOE data and this data are prepared in Excel files and in the format that BenMAP recognizes.

\section{Adverse Health Effects}

This step involves input data of baseline incidence rate which is related to the current number of health effects per person in a certain population per unit of time associated with the level of $\mathrm{PM}_{10}$ in the Iskandar Malaysia region. Table 1 shows the list of health effects that increases with an increased in $\mathrm{PM}_{10}$ level according to the epidemiologic studies done in some Asian countries which will be used in the analysis of this research. With reference to Eq. 1 of health impact functions, this research will later use the beta coefficient for each health endpoint in the list of studies stated below. These health effects are identified based on International Classification for Diseases (ICD-10) codes by WHO to ease the research process analysis and data obtaining process in the future.

Table 1: List of health effects that are related to increased in PM10 level

\begin{tabular}{lll}
\hline ICD-10 codes & Health Effects & $\begin{array}{l}\text { Studies related to analysis of increased level of } \\
\text { PM }_{10}\end{array}$ \\
\hline $\begin{array}{lll}\text { For respiratory diseases } \\
\text { J40 - J42 }\end{array}$ & $\begin{array}{l}\text { Bronchitis } \\
\text { Emphysema }\end{array}$ & $\begin{array}{l}\text { Chen (2006); Hu (2001); Kan et. al. (2004); Mead } \\
\text { \& Brajer (2005); Pan et al. (2007) }\end{array}$ \\
J43 & $\begin{array}{l}\text { Agarwal et. al. (2006) } \\
\text { Other obstructive } \\
\text { pulmonary diseases } \\
\text { (COPD) }\end{array}$ & $\begin{array}{l}\text { Agarwal et. al. (2006); Jang et. al. (2006); Ko et. } \\
\text { al. (2007); Pan et. al. (2007); Yang et. al. (2007) }\end{array}$ \\
J45 - J46 & Asthma & $\begin{array}{l}\text { Agarwal et. al. (2006); Jang et. al. (2006); Kan \& } \\
\text { Chen (2003); Pan et. al. (2007); Bell et. al. (2008) }\end{array}$ \\
$\begin{array}{l}\text { For cardiovascular } \\
\text { diseases }\end{array}$ & & \\
I20 - I25 & & \\
\hline
\end{tabular}

The health effects data have rates that vary by race, ethnicity, gender, and age group. For the purpose of this research whose aim is only to quantify the monetized benefits and health benefits when a $\mathrm{PM}_{10}$ reduction scenario analysis is implemented there is no need to specifically do an analysis that considers all these parameters. 
Nadhirah Nordin, M. Rafee Majid, Ho Chin Siong \& Gakuji Kurata

Co-Benefit Modeling and Optimization of Air Pollution Control in Iskandar Malaysia: A Methodology using BenMAP

\section{Economic Costs}

Aggregation, pooling and valuation stage will be done in BenMAP to obtain the monetized benefits for the $\mathrm{PM}_{10}$ reduction scenario. Based on the BenMAP Manual Case Study for Mumbai (2006), aggregation refers to spatial combination of results from smaller areas to a larger ones, pooling refers to the mathematical combination of two or more results of health impact function into a single result, and valuation refers to applying unit values to incidence results to obtain the monetized benefits. In this stage, valuation function from epidemiologic studies are also needed in order to calculate the economic value for the each of the reduced health endpoint from the reduction scenario analysis. Completion for the previous stage which is conducting the health impact functions for each health endpoint is necessary in order to proceed to this last stage of BenMAP PM 10 reduction scenario analysis.

\section{CONCLUSION}

It is the hope of this research that it will help policymakers to propose a comprehensive framework in improving the air quality control measures for minimizing costs and maximizing benefits in the health and economic aspects. Evaluation on the current air quality improvement strategies and policies can be done to measure the effectiveness of government initiatives by referring to the results of this research when they become available. The outcome of this research is hoped to further improve the policy framework for ambient air quality in Malaysia, especially in Iskandar Malaysia. It could also help policymakers improve the current policies and reduce the number of $\mathrm{PM}_{10}$-related health cases among the exposed population. From the monetized benefits aspect, the results are expected to reveal the savings obtained from the related reductions in the number of lost workdays, hospital admissions related to respiratory and cardiovascular symptoms and emergency room visits.

\section{ACKNOWLEDGEMENTS}

The authors gratefully acknowledge the funding support for this work provided by the Ministry of Education, Malaysia and Universiti Teknologi Malaysia (UTM) under Other Grant of VOT Number R.J1300000.7301.4B145 and Japan International Cooperation Agency (JICA) under the scheme of SATREPS Program (Science and Technology Research Partnership for Sustainable Development) for the project Development of Low Carbon Scenario for Asian Region. 


\section{REFERENCES}

Abt Associates Inc. (2006). 'BenMAP Environmental Benefits Mapping and Analysis Program, Case Study: Mumbai'.

Abt Associates Inc. (2012). 'BenMAP Environmental Benefits Mapping and Analysis Program User's Manual'.

Agarwal R, Jayaraman G, Anand S and Marimuthu P. (2006). 'Assessing respiratory morbidity through pollution status and meteorological conditions for Delhi.' Environ Monit Assess. No 114: 489-504.

Dai H, Song w, Gao X, et al. (2004). 'Study on relationship between ambient $\mathrm{PM}_{10}, \mathrm{PM}_{2.5}$ pollution and daily mortality in a district in Shanghai', Journal of Hygiene Research, No. 33: 39-49.

Davidson, K., Hallberg, A., McCubbin, D., \& Hubbell, B. (2007). Analysis of PM2.5 using the Environmental Benefits Mapping and Analysis Program (BenMAP). Journal of Toxicology and Environmental Health. Part A, 70(3-4), 332-346. doi:10.1080/15287390600884982

He, K., Lei, Y., Pan, X., Zhang, Y., Zhang, Q., \& Chen, D. (2010). Co-benefits from energy policies in China. Energy, 35(11), 4265-4272. doi:10.1016/j.energy.2008.07.021

Hong CY, Chia SE, Widjaja D, et al. (2004). 'Prevalence of respiratory symptoms in children and air quality by village in rural Indonesia', Journal of Occupational Environmental Medicine, No. 46: 1174-1179.

$\mathrm{Hu}$ W, Wei FS, Teng EJ, et. al. (2001). 'The impact of air pollution on respiratory health of children and their parents'. China Environ Sci. No 20:425-428.

Hwang SS, Cho SH and Kwon HJ (2002). 'Effects of the severe Asian dust events on daily mortality during the spring of 2002, in Seoul, Korea', J Prev Med Pub Health, No 38: 197-202.

Hwang SS, Lee JH, Jung GW, et al. (2007). 'Spatial analysis of air pollution and lung cancer incidence and mortality in 7 metropolitan cities in Korea', J Prev Med Pub Health, No 40: 233-238.

Iwai K, Mizuno S, Miyasaka Y, et al. (2005). 'Correlation between suspended particles in the environmental air and causes of disease among inhabitants: Cross-section studies using the vital statistics and air pollution data in Japan', Environ Res, No 99: 106-117.

Jang AS, Kim BY, Lee CH, et. al. (2006). 'Hospital visits and admissions in patients with asthma, COPD and cardiovascular diseases according to air pollutants'. J Asthma Allergy Clin Immunol. No. 26: 233-238.

Kan H, Chen B. (2003). 'A case crossover analysis of air pollution and daily mortality in Shanghai'. J Occup Health. No. 45:119-124.

Kan HD, Chen BH, Chen CG, et. al. (2004). 'An evaluation of public health impact of ambient air pollution under various energy scenarios in Shanghai, China. Atmos Environ. No 38: 95-102.

Ko FW, Tam WW, Wong T, et. al. (2007). 'The temporal relationship between air pollutants and hospital admissions for chronic obstructive pulmonary disease in Hong Kong'. Thorax. No 62: 780-785. 
Nadhirah Nordin, M. Rafee Majid, Ho Chin Siong \& Gakuji Kurata

Co-Benefit Modeling and Optimization of Air Pollution Control in Iskandar Malaysia: A Methodology using BenMAP

Lee JT, Kim H, Hong YC, et. al. (2003). 'Air pollution and hospital admissions for ischemic heart diseases among individuals 64+ years of age residing in Seoul, Korea.' Arch Environ Health. No 58: 617-623.

Pan X, Yue W, He K \& Tong S. (2007). 'Health benefit evaluation of the energy use scenarios in Beijing, China.' Sci Total Environ. No 374: 242-251.

UKM Pakarunding. (2004). A Research Project Report A Study of Health Impact and Risk Assessment of Urban Air Pollution in the Klang Valley, Malaysia.

WHO Air Quality Guidelines for particulate matter, ozone, nitrogen dioxide and sulfur dioxide (2005)

Yang CY \& Chen CJ. (2007). 'Air pollution and hospital admissions for chronic obstructive pulmonary disease in a subtropical city: Taipei, Taiwan.' Journal of Toxicology and Environmental Health A. No 70: 1214-1219. 